\title{
Image Spill-in
}

National Cancer Institute

\section{Source}

National Cancer Institute. Image Spill-in. NCI Thesaurus. Code C94912.

Phenomenon in a reconstructed image where true activity concentration of the tissue immediately adjacent to an object being studied, not displayed totally in its own corresponding pixels (voxels), appears spatially smeared into pixels (voxels) of this object. 